\title{
Correlation between Hand Grip Strength and Shoulder Power in Cricket Players
}

\author{
Dr. Sathya .P ${ }^{1}$, Dr. Vasanthi Kadhiravan ${ }^{2}$, K. S. Ramakrishnan ${ }^{3}$, Trupti Milind Vedak ${ }^{4}$ \\ ${ }^{1}$ Assistant Professor, D. Y. Patil University, School of Physiotherapy, Nerul, Navi Mumbai, India \\ ${ }^{2}$ Professor \&HOD, Department of Physical Education, University of Mumbai, Kalina, Mumbai, India
}

${ }^{3}$ HOD, Department of Kinesiotherapy \& Physical diagnosis, D. Y. Patil University, School of Physiotherapy, Nerul, Navi Mumbai, India

${ }^{4}$ Physiotherapy Intern, D. Y. Patil University, School of Physiotherapy, Nerul, Navi Mumbai, India

\begin{abstract}
The purpose of this study was to find the correlation between the hand grip strength and the shoulder power in the intercollegiatemale cricket players of age group 17, 18 and 19. A sample of 75 subjects were assessed, which includes 17 subjects of 17 years; 35 subjects of 18 years and 23 subjects of 19 years. All the participants were assessed for the height, weight, BMI, the hand grip strength of the dominant hand and the non-dominant hand was assessed with a calibrated hand held dynamometer and the shoulder power was assessed with a Closed Kinetic Chain Upper Extremity Stability Test. The results of this study indicated that there is positive correlation between the hand grip strength and the shoulder power in cricket players. The conclusion of the study is, as there is a positive correlation between hand grip strength and shoulder power, while training cricket players both should be given due importance for better performance in the game.
\end{abstract}

Keywords: Cricket players, Hand grip strength, Hand dynamometer, Shoulder power, Closed Kinetic Chain Upper Extremity Stability Test

\section{Introduction}

Cricket is one of the physically demanding sport comprised of several specialism requiring different skills and types of fitness. It requires excellent eye to hand co-ordination, upper extremity power, hand grip strength and the coordinated movements of shoulder, arms and wrists. Cricket is a game of endurance as well as strength and while batting, use of the forearm strength is very essential. ${ }^{1}$ In the batsmen, an increase in upper body strength is particularly important when executing powerful cricket strokes.

The hand does not function in isolation, and is dependent on the integrity of the shoulder and elbow complexes to allow the appropriate positioning of the hand in space to complete the task. ${ }^{2}$ Hand and forearm muscles are important in grip strength. Often overlooked or taken for granted, the strength of one's grip plays an important role in prevention of injuries and strength development. ${ }^{3}$ Hand grip strength is the result of forceful flexion of all finger joints with maximum voluntary force that the subject is able to exert under normal biokinetic conditions. ${ }^{1}$ Thus, the hand grip strength reflects the overall physical strength of the cricket player. $^{4}$

The two most commonly injured structures in cricket are the rotator cuff and the glenoid labrum. It should be clear that in order for a cricketer's shoulder to be pain free there needs to be a lot of dynamic strength and mobility of upper trunk and shoulder girdle. ${ }^{5}$ Shoulder injuries in cricket players are extremely common as they involve excessive throwing actions while bowling and fielding. The glenohumeral joint is inherently unstable due to its bony configuration and the degrees of freedom of movement. Therefore it is dependent to a great extent on ligaments and muscular structures to provide stability. High speed actions like throwing of ball requires frequent and synchronized activation of these stabilization mechanisms, especially the rotator cuff muscles. ${ }^{6}$ Studies have shown that shoulder itself contributes $25 \%$ to the release of the ball while throwing or batting. ${ }^{7}$

The highly developed levels of sport in the modern times require a cricket player to have strong shoulders and arms to play excellent game. Some of the proven benefits of added strength for a cricketer are: 1)prevent injury 2)increase bowling speed 3)increase throwing distance 4)reduce the effects of fatigue 5)improve bat speed. ${ }^{7}$

Grip strength is evaluated as a component of hand function in most of the sport. It is one of the best indicators of the overall strength of the limb ${ }^{\mathbf{8 , 1 5}}$ Grip strength is the integrated performance of muscles that can be produced in one muscular contraction. It is widely accepted that grip strength provides an objective index of the functional integrity of the upper extremity. ${ }^{8}$ The most common method of assessment for grip strength is the use of a hand held dynamometer. Hand held grip dynamometry is used to measure the muscular force generated by the flexor mechanism of the hand and the forearm. ${ }^{9}$

The closed kinetic chain upper extremity stability (CKCUES) test is a performance test that provides quantitative data(score) for upper extremity task in closed kinetic chain (CKC) with no needs of high technology to be realized in sportive or clinical settings. The test consists in counting how many times, during fifteen seconds, the subject assuming a push -up position is able to touch his supporting hand with the swinging hand. This test is considered easy for the clients to understand..$^{10}$

There are many studies done on the grip strength and the shoulder powerseparately in different sports. But there are very few studies done on correlation between the grip 


\section{International Journal of Science and Research (IJSR) \\ ISSN (Online): 2319-7064 \\ Index Copernicus Value (2013): 6.14 | Impact Factor (2014): 5.611}

strength and the shoulder power. Therefore the need of this study was to find the correlation between the grip strength and the shoulder power in inter-collegiate malecricket players.

\section{Problem Definition}

\section{Aim}

To find the correlation between the hand grip strength and the shoulder power in cricket players.

\section{Objectives}

- To assess the hand grip strength in cricket players.

- To assess the shoulder power with closed kinetic chain upper extremity stability test (CKCUEST) in cricket players.

- To find the correlation between the hand grip strength and the shoulder power in cricket players.

\section{Methodology}

\subsection{Study Setting}

Matunga Gymkhana, Shivaji Park cricket ground.

\section{2sample Size}

75

\subsection{Sampling Technique}

Convenient sampling

\subsection{Study Duration}

6 months

\section{5inclusion Criteria}

1) Inter collegiate male cricket players between age group 17-19

2) Male cricket players who do not have any previous injuries.

3) Players who are playing cricket since 3 to 5 years.

\subsection{Exclusion Criteria}

1) Male cricket players having any medical or musculoskeletal trauma.

2) Male cricket players having any past history of neurological involvement of upper extremity.

3) Male cricket players having any past surgical history of upper extremity.

\subsection{Ethical Approval}

The study was approved by the Institutional Ethics and Research Committee at D Y Patil University. Written informed consent was taken from all the subjects and their identification information that was collected during has been kept strictly confidential.

\subsection{Procedure}

Demographic details of the subjects such as age, height and weight were collected and BMI was calculated.The subjects were recruited from Shivaji Park cricket ground and from Matunga gymkhana playground. The subjects were well informed about the need for this study.

Hand grip strength of the subject was assessed by the hydraulic hand held dynamometer with the following position and procedure:-

A calibrated hand held hydraulic Dynamometer with adjustable grip was used. The subjects were seated in a chair with back support and with their shoulder adducted and neutrally rotated, elbow flexed at $90^{\circ}$, forearm and wrist in neutral position. Initially the procedure was explained and demonstration was shown to the subjects. The subjects were then asked to hold the dynamometer alternatively in right and then left hand, at their side without touching the rest of the body, and squeeze it forcefully. The subject then holds the dynamometer in the right and then the left hand with the arms at right angles and the elbow by the side of the body. Three trials were taken and the mean was calculated of these three trials and was taken as the mean grip strength which was calculated of both the dominant and the non-dominant hand.

Closed kinetic chain upper extremity stability test by the following procedure:-

2 strips of athletic tape are placed parallel to each other (36 inches apart) on the floor and the procedure was explained and demonstrated to the subjects. The starting position for the test is with one hand on each piece of tape while assuming a pushup position. The subjects were instructed that from the starting position they are to use one hand to reach across their body and touch the piece of tape lying under the opposing hand. After touching the tape, the hand is returned to the original starting position. The subject then performs the same movement with the other hand. Touches are counted as every time the hand reaches across the subject's body and touches the tape in the total time of 15 seconds. Three trials were taken and the average of all the three touches was calculated. Shoulder power was calculated by following formula: Power $=68 \%$ weight*average no. of lines touched/15.

\section{Result}


International Journal of Science and Research (IJSR)

ISSN (Online): 2319-7064

Index Copernicus Value (2013): 6.14 | Impact Factor (2014): 5.611

\begin{tabular}{|c|c|c|c|c|c|c|c|c|c|}
\hline & & \multirow[t]{2}{*}{$\mathrm{N}$} & \multirow{2}{*}{ Mean } & \multirow{2}{*}{$\begin{array}{c}\text { Std. } \\
\text { Deviation }\end{array}$} & \multirow[t]{2}{*}{ Std. Error } & \multicolumn{2}{|c|}{\begin{tabular}{|c|}
$95 \%$ Confidence Interval for \\
Mean
\end{tabular}} & \multirow[t]{2}{*}{ Minimum } & \multirow[t]{2}{*}{ Maximum } \\
\hline & & & & & & Lower Bound & Upper Bound & & \\
\hline \multirow{4}{*}{ RTGPST } & $17 \mathrm{yrs}$ & 17 & 32.7424 & 6.41544 & 1.55597 & 29.4438 & 36.0409 & 21 & 47 \\
\hline & $18 \mathrm{yrs}$ & 35 & 34.1309 & 9.36624 & 1.58318 & 30.9134 & 37.3483 & 17 & 55.66 \\
\hline & $19 \mathrm{yrs}$ & 23 & 36.3596 & 6.11083 & 1.2742 & 33.717 & 39.0021 & 27 & 48.66 \\
\hline & Total & 75 & 34.4996 & 7.88393 & 0.91036 & 32.6857 & 36.3135 & 17 & 55.66 \\
\hline \multirow{4}{*}{ LTGPST } & $17 \mathrm{yrs}$ & 17 & 31.4876 & 7.62626 & 1.84964 & 27.5666 & 35.4087 & 20.33 & 48.33 \\
\hline & 18 yrs & 35 & 33.0549 & 9.28878 & 1.57009 & 29.8641 & 36.2457 & 17.66 & 56.66 \\
\hline & $19 \mathrm{yrs}$ & 23 & 37.0696 & 6.06638 & 1.26493 & 34.4463 & 39.6929 & 27.33 & 52.66 \\
\hline & Total & 75 & 33.9308 & 8.24348 & 0.95187 & 32.0341 & 35.8275 & 17.66 & 56.66 \\
\hline \multirow{4}{*}{ SPWR } & $17 \mathrm{yrs}$ & 17 & 50.0532 & 12.29349 & 2.98161 & 43.7324 & 56.3739 & 33.13 & 72.52 \\
\hline & 18 yrs & 35 & 53.5569 & 16.07789 & 2.71766 & 48.0339 & 59.0798 & 24.01 & 94.12 \\
\hline & $19 \mathrm{yrs}$ & 23 & 54.6027 & 14.04909 & 2.92944 & 48.5274 & 60.6779 & 32.64 & 82.49 \\
\hline & Total & 75 & 53.0834 & 14.59654 & 1.68546 & 49.725 & 56.4418 & 24.01 & 94.12 \\
\hline \multirow{4}{*}{$\mathrm{MTCH}$} & $17 \mathrm{yrs}$ & 17 & 19.8 & 3.23731 & 0.78516 & 18.1355 & 21.4645 & 15 & 26.66 \\
\hline & $18 \mathrm{yrs}$ & 35 & 19.577 & 3.17274 & 0.66156 & 18.205 & 20.949 & 15 & 27 \\
\hline & $19 \mathrm{yrs}$ & 23 & 19.8831 & 4.52048 & 0.7641 & 18.3303 & 21.436 & 13.66 & 34 \\
\hline & Total & 75 & 19.7704 & 3.82955 & 0.4422 & 18.8893 & 20.6515 & 13.66 & 34 \\
\hline
\end{tabular}

The table-1shows the ranges of the right hand grip strength (RTGPST), left hand grip strength (LTGPST), Shoulder power (SPWR) and mean touches (MTCH) of the male players of age group 17, 18 and 19 years. It also shows the mean and the standard deviation of them.

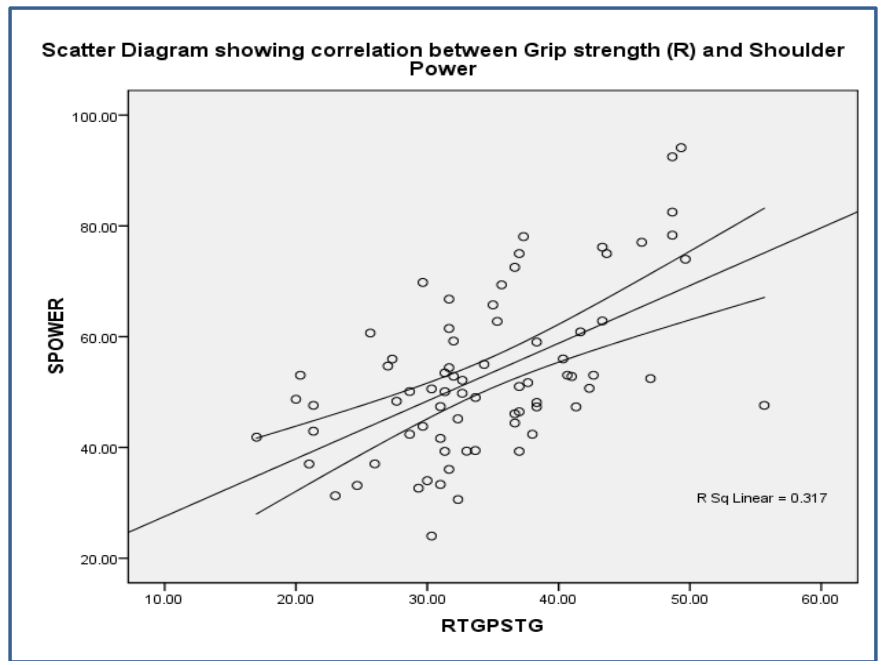

Figure 1:

The above scatter diagram shows that there is a positive correlation between the right grip strength and the shoulder power.

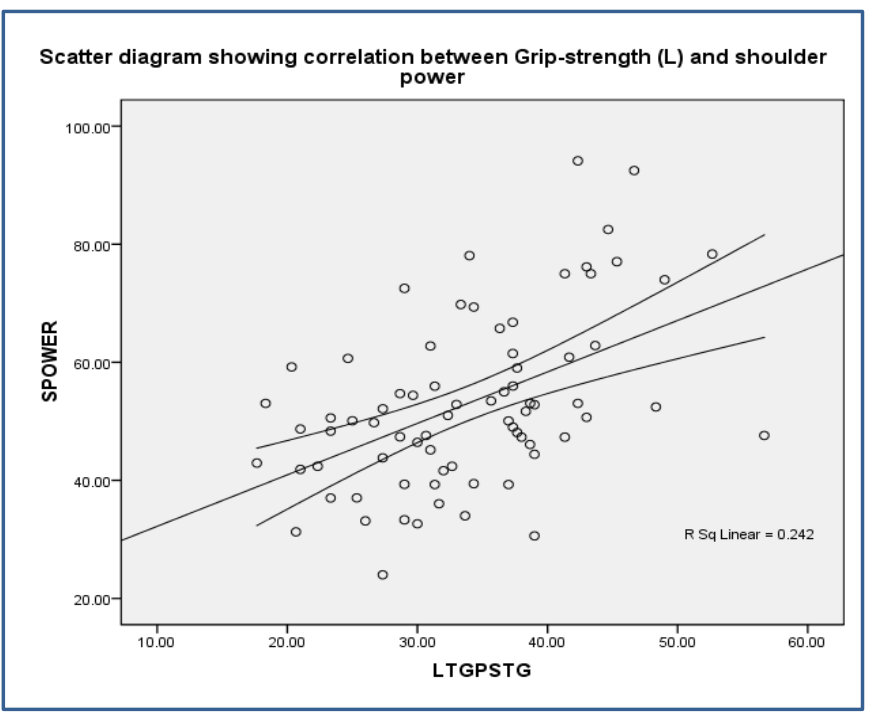

Figure 2:

The above scatter diagram shows that there is positive correlation between the left grip strength and the shoulder power.

\section{Discussion}

This study was done on 75 male inter-collegiate cricket players of the age group 17, 18 and 19 years. The objectives of the study were to find out: (a) the grip strength of the dominant hand and the non-dominant hand of cricket players by the hand held dynamometer. (b) To find the shoulder power by using closed kinetic chain upper extremity stability test (CKCUEST) and (c) To find the correlation between the grip strength and the shoulder power.

According to the first objective, from the Table- 1 , the results of this study revealed the ranges of the grip strength of the dominant hand and the non-dominant hand in the age groups

\section{Volume 5 Issue 3, March 2016}




\section{International Journal of Science and Research (IJSR) \\ ISSN (Online): 2319-7064 \\ Index Copernicus Value (2013): 6.14 | Impact Factor (2014): 5.611}

of 17,18 and 19 years. The right grip strength ranges were: (a) For 17 years: 29.44 - 36.04 with a mean of 32.74 and standard deviation of 6.41. (b) For 18 years: 30.91 - 37.34 with a mean of 34.13 and standard deviation of 9.36. (c) For 19 years: 33.71 - 39.00 with a mean of 36.35 and standard deviation of 6.11 .

The left grip strength ranges were: (a) For 17 years: 27.56 35.40 with a mean of 31.48 and standard deviation of 7.62. (b) For 18 years: 29.86 - 36.34 with a mean of 33.05 and standard deviation of 9.28. (c) For 19 years: 34.44 - 39.69 with a mean of 37.06 and standard deviation of 6.06. The above were the ranges of the dominant and the non-dominant hand grips in the male intercollegiate cricket players.

Thus from the above ranges it can be stated that as the age group increases the grip strength of both the dominant hand and the non-dominant hand. The reason could be maximal absolute and relative handgrip strength gradually increases from childhood to adulthood. ${ }^{18}$ A child not only increases in heights but also in weight, bone mass and muscle volume and thus the grip strength is increased in both the hands. ${ }^{19}$ Hand grip strength is a physiological variable that is affected by a number of factors including age, gender and body size among others. Strong correlations between grip strength and various anthropometric traits were reported earlier. Earlier studies have reported that, in case of relationships of hand grip strength with various anthropometric variables, it was found that males attain greater values for these anthropometric variables and also greater values for the grip strength. It was found that the age dependent increase of hand grip was strongly associated with changes in fat free mass during their childhood. Hand grip strength is found to be a significant determinant of bone mineral content and the bone area at the forearm sites and has a positive correlation with lean body mass and physical activity. In case of height, a positive correlation with hand grip strength can be the result of various factors such as greater height will lead to longer arms with greater lever arm for force generation, resulting in efficient amount of force. ${ }^{20}$ The grip strength may also increase as the age increases based on onset of puberty in which there is androgenic action of testosterone. ${ }^{21}$ The positive effect of physical activities on hand grip strength and the weight training of muscle increases their efficiency due to more acquisition of strength and development in adolescents. ${ }^{22}$ Thus, it is also evident from this study that the mean grip strengths of the dominant and the non-dominant hand is also increasing gradually as the age group increases.

According to the second objective, the shoulder power was calculated by using a standard closed kinetic chain upper extremity stability test (CKCUEST) which includes 3 trials of number of touches made in 15 seconds. The mean of the number of touches was calculated and then the shoulder power was calculated by using the formula:

Shoulder Power $=65 \%$ of body weight*number of touches $/ 15$ seconds.

The shoulder power ranges are from: (a) For 17 years: 43.73 - 56.37 with a mean of 50.05 and standard deviation of 12.29. (b) For 18 years: 48.03 - 59.07 with a mean of 53.55 and standard deviation of 16.07. (c) For 19 years: 48.52 60.67 with a mean of 54.60 and standard deviation of 14.04 .

The study shows an increase in the shoulder power with the increase in the age group. The probable reason could be,sport specific training with regular, repeated throwing motions while bowling and throwing the ball causes an increase of shoulder power .Regular, repeated throwing motion in many sports causes elective development of the shoulder muscles ${ }^{23}$ Strength and conditioning programs also help to enhance the shoulder power in athletes as their age increases as they regularly practice them. ${ }^{24}$

The mean of the number of touches required to assess the shoulder power in the closed kinetic chain upper extremity stability test (CKCUEST) ranges are from: (a) For 17 years: 18.13 - 21.16 with a mean of 19.80 and standard deviation of 3.23. (b) For 18 years: $18.33-21.43$ with a mean of 19.57 and standard deviation of 4.52. (c) For 19 years: 18.20-21.43 with a mean of 19.88 and standard deviation of 3.17.These are the average number of touches that were found in the inter-college cricket players of the Indian population.

The study shows that the mean values and the ranges of the touches are almost similar in all the age groups 17, 18 and 19 years.

According to the third objective of this study the correlation between the hand grip strength and the shoulder power was calculated by using Pearson correlation method, which reveals that there is a positive correlation between the hand grip strength and the shoulder power. The probable reason could be as stated by Kibler et al. that individual body segments, or links, are coordinated in their movements by muscle activity and body positions to generate, summate, and transfer force through these segments to the terminal link. This sequencing is usually termed the kineticchain. ${ }^{25}$ Thus, from this study it is evident that there is correlation between hand grip strength and shoulder power.

\section{Conclusion}

This study concludes that there is positive correlation between the hand grip strength and the shoulder power. Thus while training cricket players equal importance should be given to strength hand gripand shoulder power.

\section{References}

[1] Amandeep Singh and Vishwas Gaurav; 'Comparative Study of Hand Grip and Shoulder Girdle Among Inter College level cricket, baseball and softball players'; (International Multidisciplinary Research Journal volume 2 Issue 3. Sept 2014 ISSN NO. 2321-5488)

[2] B. Chittibabu and N. Akilan.; 'Comparison between University level cricket and handball players on right and left hand grip strength'; ( International Journal for Life Sciences and Educational Research Vol. 2(3),pp. 97-99 , July-2014 )

[3] Vengata Subramani Manoharan Et al; 'Factors affecting Hand Grip Strength and its Evaluation: A Systemic Review' ; (International Journal of 


\section{International Journal of Science and Research (IJSR) ISSN (Online): 2319-7064 \\ Index Copernicus Value (2013): 6.14 | Impact Factor (2014): 5.611}

Physiotherapy and Research 2015 vol 3 (6):128893.ISSN2321-1822)

[4] Dr. Amandeeep Singh ; 'Comparative Study of shoulder girdle strength and hand grip strength between basketball and handball players'; (Peer Reviewed Research Journal vol 1 -Issue 3 ISSN -2348-8921)

[5] www.Espncricinfo.com/gillettezone/content/story/5602 48.html

[6] Juneja, H., Verma, S. K., \& Khanna, G. L. (2011). Isometric peak force of shoulder rotators in cricketers with and without history of shoulder pain. Journal of Exercise Science and Physiotherapy, 7(1), 42.

[7] www.bodybuilding .com/fun/strength-training-forcricket.html

[8] Pravatikar Et al ; ' Comparative Study of Grip Strength in different positions of Shoulder and Elbow with Wrist in neutral and extension position'.

[9] The Importance of Grip Strength By Jason Shea C.S.C.S.,PES

[10] Tucci, H. T., Martins, J., de Carvalho Sposito, G., Camarini, P. M. F., \& de Oliveira, A. S. (2014). Closed Kinetic Chain Upper Extremity Stability test (CKCUES test): a reliability study in persons with and without shoulder impingement syndrome. BMC musculoskeletal disorders, 15(1), 1.

[11] Jared Kitamura, P. T., \& Waitsc, D. M. C. (2007). Reference values for the closed kinetic chain upper extremity stability test (CKCUEST) for collegiate baseball players.

[12] Lee, D. R., \& Kim, L. J. (2015). Reliability and validity of the closed kinetic chain upper extremity stability test. Journal of physical therapy science, 27(4), 1071.

[13] Negrete, R. J., Hanney, W. J., Kolber, M. J., Davies, G. J., Ansley, M. K., McBride, A. B., \& Overstreet, A. L. (2010). Reliability, minimal detectable change, and normative values for tests of upper extremity function and power. The Journal of Strength \& Conditioning Research, 24(12), 3318-3325.

[14] Negrete, R. J., Hanney, W. J., Kolber, M. J., Davies, G. J., \& Riemann, B. (2011). Can upper extremity functional tests predict the softball throw for distance: a predictive validity investigation. International journal of sports physical therapy, 6(2).

[15] P. SATHYA, RAMAKRISHNAN K. S, S. MAKESH BABU, S. K. V. V. (2014). POWER WEB, RESISTIVE HAND EXERCISER AND HAND PUTTY EXERCISES FOR PINCH STRENGTH IN DENTAL PROFESSIONALS. International Journal of Humanities, Arts, Medicine and Sciences, 2(7), 13-20.

[16] Mathiowetz, V., Wiemer, D. M., \& Federman, S. M. (1986). Grip and pinch strength: norms for 6-to 19year-olds. American Journal of Occupational Therapy, 40(10), 705-711.

[17] Tucci, H. T., Martins, J., de Carvalho Sposito, G., Camarini, P. M. F., \& de Oliveira, A. S. (2014). Closed Kinetic Chain Upper Extremity Stability test (CKCUES test): a reliability study in persons with and without shoulder impingement syndrome. BMC musculoskeletal disorders, 15(1),1.

[18] Gerodimos, V. (2012). Reliability of handgrip strength test in basketball players. Journal of human kinetics, 31, 25-36.
[19] Molenaar, H. M., Selles, R. W., Willemsen, S. P., Hovius, S. E., \& Stam, H. J. (2011). Growth diagrams for individual finger strength in children measured with the RIHM. Clinical Orthopaedics and Related Research ${ }^{\circledR}$, 469(3), 868-876.

[20] Shyamal, K., Ghandi, M., \& Singh, A. P. (2008). An association of hand grip strength with height, weight and BMI in boys and girls aged 6-25 years of Amritsar, punjab, india. The Internet Journal of Biological Anthropology, 2(1).

[21] Ferreira, A. C. D. C., Shimano, A. C., Mazzer, N., Barbieri, C. H., Elui, V. M. C., \& Fonseca, M. D. C. R. (2011). Grip and pinch strength in healthy children and adolescents. Acta Ortopédica Brasileira, 19(2), 92-97.

[22] Ruprai, R. K., Tajpuriya, S. V., \& Mishra, N. (2016). Handgrip strength as determinant of upper body strength/physical fitness: a comparative study among individuals performing gymnastics (ring athletes) and gymnasium (powerlifters). International Journal of Medical Science and Public Health, 5(6).

[23] Pontaga, I., \& Zidens, J. (2014). Shoulder Rotator Muscle Dynamometry Characteristics: Side Asymmetry and Correlations with Ball-Throwing Speed in Adolescent Handball Players. Journal of human kinetics, 42(1), 41-50.

[24] The Athlete's Shoulder ;By Kevin E. Wilk, Michael M. Reinold , James Rheuben Andrews.

[25] Kibler, W. B. (1998). The role of the scapula in athletic shoulder function. The American journal of sports medicine, 26(2), 325-337.

\section{Author Profile}

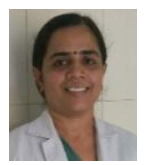

Dr P Sathya, Assistant Prof at School of physiotherapy, DY Patil university, Navi Mumbai, India is a post graduate from 2001 and has over 14 years of teaching experience

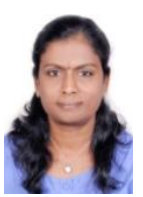

Dr Vasanthi Kadhiravan, PhD, Professor \& Head, Department of Physical Education, University of Mumbai, India is an eminent academician with a teaching experience of over 22 years

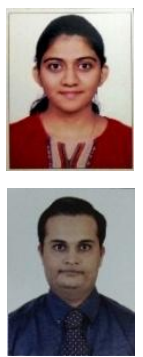

Ms. Trupti Milind Vedak is an intern student pursuing Bachelors in Physiotherapy at School of Physiotherapy, DY Patil University, Navi Mumbai

Dr K S Ramakrishnan, Prof at School of physiotherapy, DY Patil university, Navi Mumbai, India and has over 14 years of teaching experience 